\title{
CARACTERIZAÇÃO ULTRASSONOGRÁFICA, CITOLÓGICA E ANÁTOMOPATOLÓGICA DE NÓDULOS DE TIREÓIDE CLASSIFICADOS POR CITOLOGIA COMO INDETERMINADOS.
}

\author{
Wendy M. F. Tirapani*, Cínthia M. Riguetto, Ilka M. B. Botelho, Elizabeth J. Pavin, Icleia Barreto, Denise E. \\ Zantut-Wittmann
}

\section{Resumo}

A classificação de Bethesda para citologia de tireoide ( $\mathrm{BI}=$ material insuficiente, $\mathrm{BI}=$ =benigno, BIII e BIV=indeterminados, $\mathrm{BV}=$ suspeito de malignidade, $\mathrm{BVI}=$ maligno) visa uniformizar diagnósticos e facilitar a comunicação entre médicos patologistas e clínicos. As classes indeterminadas BIII e BIV não possuem risco de malignidade suficiente que justifique a imediata intervenção cirúrgica, enquanto que BV apresenta maior risco de malignidade, demanda indicação cirúrgica, mas as lesões podem ser benignas.O presente estudo compara as classes de citologias indeterminadas quanto às características demográficas, ultrassonográficas (US), anatomopatológicas (AP) e em relação à malignidade de pacientes operados por nódulo de tireoide. Trata-se de estudo retrospectivo de 238 pacientes em que as citologias indeterminadas apresentaram ao AP maior frequência de nódulos não encapsulados, extensão extra-tireoidiana, invasão vascular e linfonodos metastáticos, ausentes nas benignas. Entre as características citológicas de padrão indeterminado, células oncocíticas estavam presentes apenas em nódulos malignos ao AP. US não diferenciou nódulos de citologia indeterminada e benigna.

Palavras-chave: Citologia, Bethesda, nódulo de tireóide, câncer de tireoide.

\section{Introdução}

A citologia é o melhor método para discernir nódulos de tireoide benignos e malignos. Atualmente, o diagnóstico citológico encontra-se mais uniforme seguindo a classificaçao de Bethesda $(\mathrm{Bl}=$ material insuficiente, $\mathrm{Bl}=$ =benigno, $\mathrm{BIII}$ e $\mathrm{BIV}=$ indeterminados para malignidade, $\mathrm{BV}=$ suspeito de malignidade, $\mathrm{BVI}=$ maligno). No entanto, as citologias indeterminadas permanecem como um importante problema diagnóstico. O presente estudo compara as classes de citologias indeterminadas quanto às características demográficas, ultrassonográficas, anatomopatológicas e em relação à malignidade de pacientes operados por nódulo de tireoide. Ainda, propõe a identificação de fatores de risco em relação à presença de malignidade.

\section{Resultados e Discussão}

Estudo retrospectivo de 238 pacientes, sendo 209 mulheres (87,81\%), acompanhados no Ambulatório de Nódulo de tireoide, Endocrinologia, HC-UNICAMP. Em pacientes com nódulos de tireoide classificados citologicamente pelo sistema de Bethesda, BII e BIII foram mais frequentes nas mulheres e BIV e BV, nos homens. Pacientes com nódulos Blll eram mais velhos do que os BV. Quanto às características US, não encontramos diferenças entre as classes citológicas. Quanto às características AP, todos os Bll eram nódulos encapsulados, sendo não encapsulados os BIII, IV e V. Extensão extra-tireoidiana, invasão vascular e linfonodos metastáticos foi ausente em BII, mas presente em BV, BIV e BIII. (Tabela 1)

A comparação entre nódulos de tireoide benignos e malignos ao AP, mostrou maior porcentagem de malignidade no sexo masculino vs feminino $(20,87 \% v s 2,91 \%, p<0.0001)$ e que pacientes com nódulos benignos vs malignos eram mais velhos $(p=0,0022)$. As características US não diferenciaram nódulos benignos e malignos. Entre as características citológicas dos nódulos BIII, IV e V, apenas a presença de células oncocíticas foi mais frequente em malignos vs benignos $(29,96 \%$ vs0\%, $p=0,0003)$. Ao AP, a multifocalidade ocorreu em $31,3 \%$ dos nódulos malignos vs $3,39 \%$ dos benignos $(p<0.0001)$.

A análise de regressão de Cox incluindo variáveis demográficas, US e de citologia indeterminada identificou que o sexo masculino apresentou razão de risco para malignidade 8,772 vezes maior do que o feminino $(p=0,0006 ; 2.564-30.303)$ e que a cada ano a mais na idade do paciente houve $9,76 \%$ maior risco para malignidade $(p=0,0084 ; 0,958$ 0,994).

A análise das categorias da classificação de Bethesda mostrou que $100 \%$ das citologias Bll eram nódulos benignos ao anatomopatológico, e entre as citologias indeterminadas, comprovou-se malignidade em $20 \%$ das BIII, $100 \%$ das BIV e $95,65 \%$ das BV (Tabela 2 ).

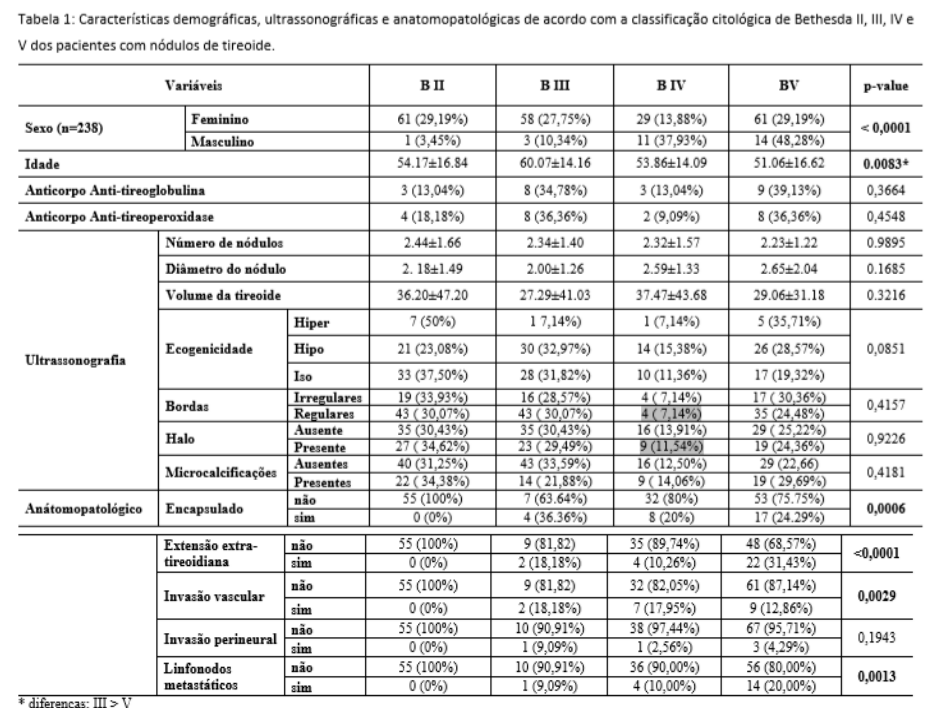

Tabela 2. Frequência das categorias da classificação de Bethesda II,III, IV e V em relação a nódulos benignos e malignos ao exame anatomopatológico.

\begin{tabular}{l|c|c}
\hline \multicolumn{1}{c|}{ CITOLOGIA } & BENIGNO & MALIGNO \\
\hline Bethesda II (N=62) & $62(100 \%)$ & $0(0 \%)$ \\
\hline Bethesda III (N=45) & $36(80 \%)$ & $9(20 \%)$ \\
\hline Bethesda IV (N=40) & $0(0 \%)$ & $40(100 \%)$ \\
\hline Bethesda V (N=69) & $3(4,35 \%)$ & $66(95,65 \%)$ \\
\hline
\end{tabular}

\section{Conclusões}

As características anatomopatológicas foram diferentes entre categorias citológicas de Bethesda benigna e indeterminadas, sendo que as indeterminadas apresentaram maior frequência de nódulos não encapsulados, com extensão extra-tireoidiana, invasão vascular e linfonodos metastáticos.

- Entre as características citológicas de padrão indeterminado, a presença de células oncocíticas foi verificada apenas em nódulos malignos ao anatomopatológico.

- As características ultrassonográficas não foram diferentes entre as categorias citológicas de Bethesda benigna e indeterminadas ou entre nódulos benignos e malignos.

Sexo masculino e maior idade foram fatores de risco para malignidade. 